\title{
Desinfecção com amônia quaternária associada à fermentação não potencializa o controle de coccidiose em cama de frango
}

\author{
Disinfection with quaternary ammonia associated with fermentation enhances do not control \\ coccidiosis in poultry litter
}

\author{
Rafaela Carolina Lopes Assis ${ }^{\text {* }^{*}}$ Fábio Dias Luns ${ }^{\mathrm{II}}$ Márcia Cristina Cury ${ }^{\mathrm{I}}$
}

\section{RESUMO}

\begin{abstract}
O objetivo deste estudo foi avaliar se o uso da desinfecção com amônia quaternária associada à fermentação potencializa o controle de oocistos na cama de frangos de corte. A cama de frango reutilizada passou pela fermentação elou desinfecção com amônia quaternária no intervalo sanitário de 15 dias entre dois alojamentos sucessivos de 160 frangos cada. No $1^{\circ}$ alojamento, as aves foram inoculadas, por via oral, com $3 \times 10^{3}$ oocistos de Eimeria acervulina aos 12 dias de idade. Com a saída desse lote, a área de alojamento foi dividida em 4 boxes de $5 \mathrm{~m}^{2}$ cada. Cada box representou um grupo de tratamento da cama: grupo 1: a cama não passou por tratamento (controle); grupo 2: fermentação; grupo 3: desinfecção; e grupo 4: desinfecção associada à fermentação. No $2^{\circ}$ alojamento, outras 160 aves foram divididas nos boxes. Foram realizadas contagens de oocistos por grama de fezes (OOPG), determinação do período pré patente, observação de lesões intestinais, avaliação de ganho de peso e da conversão alimentar. Os resultados demonstraram que não houve redução do número de oocistos recuperados da cama somente desinfetada $\left(G 3: 2,26 \times 10^{6}\right)$ em relação à cama não tratada (G1: $\left.2,54 \times 10^{6}\right)$. Os grupos em que a cama foi fermentada (G2 e G4) apresentaram significativa redução do número de oocistos em relação ao grupo controle, no entanto, a cama fermentada e desinfetada $($ G4: 0,76x10 $)$ não apresentou diferença significativa na redução do número de oocistos quando comparada à cama somente fermentada $\left(G 2: 0,67 \times 10^{6}\right)$. Conclui-se que a desinfecção com amônia quaternária associada à fermentação da cama não potencializa o controle da coccidiose aviária.
\end{abstract}

Palavras-chave: coccidiose aviária, desinfetantes, sanidade, oocistos, Eimeria acervulina.

\section{ABSTRACT}

The objective of this study was to evaluate if the use of quaternary ammonium associated with the fermentation cause synergism in control of oocysts of poultry litter. The poultry litter recycled went through fermentation and/or disinfection with quaternary ammonium in sanitary interval between two successive housings of 160 chickens each. In the first housing, the birds were inoculated orally with $3 \times 10^{3}$ Eimeria acervulina oocysts at 12 days old. With the removal of these birds, the housing area was divided into four pens of $5 \mathrm{~m}^{2}$ each. Each pen represents a treatment group of the litter: group 1: untreated (control), group 2: fermentation, group 3: disinfection and group 4: disinfection and fermentation. It was counted oocysts per gram of faeces $(O O P G)$, determination of pre patent, intestinal lesions score, weight gain and feed conversion. The results showed no reduction in the number of oocysts recovered from the single litter only (G3: $\left.2.26 \times 10^{6}\right)$ in relation to untread litter $\left(G 1: 2.54 \times 10^{6}\right)$. Groups in which the litter was fermented (G2 and G4) showed significant reduction of oocysts in the control group, however, the fermented and desinfected litter (G4: $\left.0.76 \times 10^{6}\right)$ showed no significant difference in reducing the number of oocysts compared to single fermented litter $\left(G 2: 0.67 \times 10^{6}\right)$. It follows that the desinfection with quaternary ammonium associated to fermentacion of the litter does not potentiate the control of avian coccidiosis.

Key words: avian coccidiosis, disinfectant, health, oocysts, Eimeria acervulina.

\section{INTRODUÇÃO}

A coccidiose é uma das mais comuns e importantes doenças da indústria avícola mundial causada por protozoários parasitas do gênero Eimeria spp. que infecta as células epiteliais intestinais e se manifesta clinicamente por diarreia, perda de peso e mortalidade (KAWAZOE et al., 2005). As perdas econômicas estão ligadas à piora da conversão alimentar, diminuição do ganho de peso, morbidade e mortalidade das aves (GABRIEL et al., 2006).

\footnotetext{
'Laboratório de Parasitologia, Instituto de Ciências Biomédicas, Universidade Federal de Uberlândia (UFU), Av. Pará, 1720, Campus

Umuarama, 38400-902, Uberlândia, MG, Brasil. E-mail: rafaelalopesassis@yahoo.com.br. *Autor para correspondência.

IUniversidade Federal de Viçosa (UFV), Viçosa, MG, Brasil. 
Os atuais sistemas de produção intensiva facilitam a multiplicação de patógenos, devido à alta densidade populacional e ao curto ciclo produtivo, o que facilita a contaminação ambiental e a reinfecção das próprias aves. A reutilização da cama na produção de frangos de corte é uma prática adotada para diminuir custos com a aquisição de camas novas e para aumentar a quantidade de nutrientes nesta, para posterior utilização como biofertilizante na agricultura. Também é uma forma de estabilizar ou diminuir o impacto ambiental, ao reduzir a quantidade de camas por ave produzida. No Brasil, é comum a reutilização da cama por lotes consecutivos, porém, este manejo pode trazer impactos negativos referentes à manutenção de agentes patogênicos na cama reutilizada (SANTOS et al., 2005). Entre os métodos de controle de parasitos na cama reutilizada, merece destaque a fermentação, método comumente praticado na avicultura industrial (COSTA \& ÁVILA, 2003). A desinfecção da cama de frango também é um método comumente utilizado nas granjas avícolas, no entanto, não existem trabalhos que avaliem a real efetividade dessa prática no controle da coccidiose. Torna-se necessária a avaliação da efetividade de métodos preventivos de controle frente ao desafio da coccidiose e o seu impacto sobre o plantel avícola. Este trabalho objetivou a avaliação da eficiência da desinfecção por amônia quaternária associada à fermentação da cama de frango no controle da coccidiose em frangos de corte.

\section{MATERIAL E MÉTODOS}

A cepa Ea3LPL8a de E. acervulina, foi cedida pela Empresa Brasileira de Pesquisa Agropecuária (EMBRAPA). O Centro Técnico de Reprodução de Eimerias, do Laboratório BIOVET, Brasil, executou a purificação e ajuste do isolado (STROUT et al., 1965). As aves foram inoculadas com $0,5 \mathrm{~mL}$ de solução contendo $3 \times 10^{3}$ oocistos esporulados. Frangos de corte da linhagem Cobb, fêmeas, com um dia de idade, vacinadas no incubatório contra doença de Marek, Bronquite e Gumboro, foram utilizados neste estudo. O peso médio alojado foi de 42 gramas.

O estudo foi realizado em dois alojamentos consecutivos de 160 aves cada, no mesmo galpão com cama de frango de palha de arroz em uma espessura de $10 \mathrm{~cm}$. Todos os 160 frangos do $1^{\circ}$ alojamento foram inoculados experimentalmente, aos 12 dias de idade, com $3 \times 10^{3}$ oocistos da cepa Ea3LPL8a de E. acervulina, individualmente por via oral, através de uma cânula esofágica acoplada a uma seringa de insulina de $1 \mathrm{~mL}$. Essas aves foram introduzidas para produzir uma cama contaminada e foram retiradas do galpão aos 35 dias de idade. Um intervalo sanitário de 15 dias foi estabelecido para realização dos diferentes tratamentos preventivos nesta cama reutilizada, que foi uniformemente dividida entre quatro boxes, no $2^{\circ}$ alojamento, separados por placas de madeira. Realizaram-se as seguintes metodologias nos boxes: grupo 1 (G1): controle positivo, a cama de frango não foi tratada; grupo $2(\mathrm{G} 2)$ : a cama foi submetida ao método de fermentação, que consistiu no amontoamento e cobertura sob lona plástica por 10 dias consecutivos; grupo 3 (G3): desinfecção da cama com solução de amônia quaternária a $10 \%$ (cloreto de benzalcônio) em diluição de 1:20, em duas aplicações de 15 minutos, no $2^{\circ}$ e $12^{\circ}$ dias do intervalo sanitário; grupo 4 (G4): fermentação da cama (metodologia do grupo 2), seguida de desinfecção por amônia quaternária (metodologia do grupo 3). Após os tratamentos da cama, iniciou-se o $2^{\circ}$ alojamento, no qual outros 160 frangos foram distribuídos nesses grupos (40 aves/grupo). Nesse $2^{\circ}$ alojamento, as aves foram contaminadas naturalmente através da cama utilizada no 1o alojamento. Aos 21 dias de idade, 10 aves de cada grupo foram necropsiadas para avaliação de lesões intestinais. As 30 aves restantes em cada grupo foram mantidas até os 35 dias de idade, para acompanhamento da curva de eliminação de oocistos e do desempenho zootécnico.

Amostras de fezes e cama contidas em cada grupo foram coletadas diariamente, sendo obtidas em seis locais dos boxes experimentais (quatro amostras laterais e duas centrais), para determinação do período pré patente e curva de eliminação de oocistos. Realizou-se a técnica de SHEATER (1923) modificada, com as amostras de fezes e os oocistos recuperados foram quantificados em câmara de McMaster. O número total de oocistos foi calculado usando a seguinte fórmula: [número total de oocistos $=$ oocistos contados $\mathrm{x}$ fator de diluição $\mathrm{x}$ (volume da amostra de fezes/volume contido na câmara)/número de aves por grupo]. $\mathrm{O}$ peso médio das aves foi mensurado, semanalmente, do $1^{\circ}$ até os 35 dias de idade. $\mathrm{O}$ consumo de ração final foi mensurado para determinar a conversão alimentar real e ajustada pela seguinte fórmula: CA ajustada $2,00=((2,00-\mathrm{PV}) / 3)+\mathrm{CA}$ real, em que: CA ajustada 2,00 = Conversão alimentar ajustada para 2,00 quilos de peso vivo, $\mathrm{PV}=$ peso vivo das aves, $\mathrm{CA}=$ conversão alimentar real obtida pelas aves.

Nos animais pertencentes ao $2^{\circ}$ alojamento, aos 21 dias de idade, foram coletados os duodenos de 10 frangos/grupo, sendo submetidos à 
avaliação macroscópica para observação de lesões e quantificação do escore, baseado em método previamente descrito por JOHNSON \& REID (1970), em que o escore zero equivale à ausência de lesões e o escore quatro é o mais severo, indicando lesões pontuais ou estriadas brancas completamente coalescentes, mucosa intestinal acinzentada, parede engrossada e conteúdo cremoso.

Os resultados obtidos foram submetidos à avaliação estatística, segundo a análise de variância (ANOVA). Os dados foram transformados em escala logarítmica $(\log -10)$ e submetidos ao teste de Tukey em nível de $5 \%$ de significância $(\mathrm{P}<0,05)$. O teste de Kruskal-Wallis $(\mathrm{P}<0,05)$ foi utilizado para variáveis qualitativas.

\section{RESULTADOS E DISCUSSÃO}

O período pré patente da eliminação de oocistos observado neste estudo foi de 120 horas, semelhante aos descritos por KAWAZOE et al. (2005) e GABRIEL et al. (2006). Períodos pré patentes, variando entre 96 e 120 horas, são comumente relatados na infecção por $\boldsymbol{E}$. acervulina, com variações referentes à cepa estudada (KAWAZOE et al., 2005). A cinética de eliminação de oocistos, observada neste trabalho, foi característica do ciclo biológico desse parasito, sendo observados picos de eliminação no 7oㅡ e no $15^{\circ}$ dias após a infecção (DAI). Os valores de oocistos recuperados no pico primário de eliminação (7ํDAI) e no pico secundário (15DAI), respectivamente, para os grupos $\mathrm{G} 1$, em que a cama não passou por tratamento, foram: $7,95 \times 10^{6}\left(2,31 \times 10^{3}\right)$; $3,52 \times 10^{6}\left(2,26 \times 10^{3}\right)$ e $\mathrm{G} 3$, no qual a cama foi somente desinfetada com amônia: $6,21 \times 10^{6}\left(2,78 \times 10^{3}\right)$; $2,89 \times 10^{6}\left(3,01 \times 10^{3}\right)$ foram significativamente maiores do que os valores encontrados nos picos dos grupos G2 (cama fermentada): $4,23 \times 10^{6}\left(3,63 \times 10^{3}\right) ; 1,96 \times 10^{6}$ $\left(2,70 \times 10^{3}\right)$ e $\mathrm{G} 4$ (cama fermentada e desinfetada): $4,49 \times 10^{6}\left(2,14 \times 10^{3}\right) ; 2,12 \times 10^{6}\left(2,15 \times 10^{3}\right)$

Observou-se que os valores de oocistos dos grupos G1 $\left(2,54 \times 10^{6}\left(4,40 \times 10^{3}\right)\right)$ e G3 $\left(2,26 \times 10^{6}\right.$ $\left.\left(4,35 \times 10^{3}\right)\right) \quad$ apresentaram-se estatisticamente maiores que os encontrados nos grupos G2 $\left(0,67 \times 10^{6}\left(2,38 \times 10^{3}\right)\right)$ e $\mathrm{G} 4\left(0,76 \times 10^{6}\left(2,21 \times 10^{3}\right)\right)$ $(\mathrm{P}<0,05)$. Observou-se ainda que os valores de oocistos recuperados do grupo no qual a cama foi apenas desinfetada (G3) não apresentou diferença significativa com o grupo controle $(\mathrm{G} 1)$, no qual não foi realizado nenhum tratamento na cama $(\mathrm{P}<0,05)$. Esse resultado demonstrou que a desinfecção da cama com amônia quaternária não possui efetividade no controle da coccidiose causada por E. acervulina. A média de oocistos recuperados no G4, no qual a cama foi fermentada e desinfetada, foi estatisticamente igual a do G2 $(\mathrm{P}<0,05)$. Esses resultados permitem afirmar que a amônia quaternária não foi eficiente associada à fermentação, ou seja, a desinfecção não potencializa o efeito da fermentação na redução da carga infectante de oocistos expostos as aves.

A fermentação é um método comumente utilizado para diminuir patógenos em sistemas avícolas. O amontoamento e cobertura da cama de frango causam aumento da temperatura, que atinge até $70^{\circ} \mathrm{C}$ (OVIEDO-RONDÓN, 2008). De acordo com WICHUK \& McCARTNEY (2007), a inativação de oocistos ocorre à temperatura acima de $55^{\circ} \mathrm{C}$ por um tempo mínimo de três dias. Neste estudo, a fermentação foi realizada com o binômio tempotemperatura adequado à inativação de oocistos, o que pode ser comprovado pela redução da carga infectante de oocistos nos grupos de cama fermentada. De acordo com PENG et al. (2008), a diminuição de oocistos também pode ser potencializada pela presença de microrganismos fecais, como bactérias associadas à fermentação.

A desinfecção com amônia quaternária não causou nenhum efeito como método de controle dos oocistos de E. acervulina na cama de frangos de corte. Apesar de alguns compostos a base de amônia, como o anidro de amônia $\left(\mathrm{H}_{3} \mathrm{~N}\right)$ e o hidróxido de amônia $\left(\mathrm{NH}_{4} \mathrm{OH}\right)$, apresentarem comprovada ação sobre oocistos, esta atividade foi comprovada somente em estudos in vitro (GUIMARÃES et al., 2007). Em estudos in vivo, a matéria orgânica do ambiente interage com o princípio ativo do desinfetante, causando a redução do poder da desinfecção (WICHUK, 2007). Neste estudo, as fezes, penas e a própria cama de frango podem ter causado redução do poder desinfetante da amônia quaternária. Além disso, a ação da amônia quaternária pode ter sido limitada pelo baixo tempo de exposição ao desinfetante e influenciada pelo tamanho e carga iônica da molécula de amônia quaternária (DAUGSCHIES et al., 2002), impossibilitando a passagem desta pela parede do oocisto.

A eliminação média de oocistos nas fezes e o desempenho do peso das aves são os parâmetros de infecção mais seguros para mensuração dos efeitos da coccidiose (CHAPMAN et al., 2005). As tabelas 1 e 2 apresentam o desempenho zootécnico (conversão alimentar e ganho de peso semanal) obtido nos diferentes grupos estudados. Neste estudo, notou-se queda de desempenho zootécnico dos frangos devido à infecção coccidiana. Aves com coccidiose apresentam redução no ganho de peso e piora da conversão alimentar, porque as células 
Tabela 1 - Valores médios da conversão alimentar real (CR) e conversão ajustada (CAj) dos frangos de corte infectados com Eimeria acervulina em cama reutilizada, após tratamentos de controle da coccidiose, calculados ao final do período experimental.

\begin{tabular}{lcc}
\hline Tratamentos & Conversão Real (CR) & Conversão Ajustada (CAj) \\
\hline G1 (Controle) & $1.897 \mathrm{~b}$ & $2.080 \mathrm{~b}$ \\
G2 (Fermentação) & $1.765 \mathrm{a}$ & $1.903 \mathrm{a}$ \\
G3 (Amônia quaternária) & $1.841 \mathrm{~b}$ & $1.996 \mathrm{~b}$ \\
G4 (Ferm. + Amônia quaternária) & $1.692 \mathrm{a}$ & $1.826 \mathrm{a}$ \\
\hline
\end{tabular}

(ab)Valores do mesmo parâmetro seguidos de letras minúsculas diferentes na mesma coluna indicam valores estatisticamente diferentes pelo Teste Tukey $(\mathrm{P}<0,05)$. Unidade de medida: gramas $(\mathrm{g})$.

epiteliais intestinais estão infectadas, causando redução de absorção (CHAPMAN et al., 2005). A tabela 2 apresenta os valores médios dos pesos semanais, que foram realizados aos sete, 14, 21, 28 e 35 dias de vida dos frangos e demonstra que houve diferença significativa $(\mathrm{P}<0,05)$ nos dois primeiros pesos semanais (sete e 14 dias) entre os grupos de fermentação da cama (G2 e G4) e os demais grupos (G1 e G3). O desempenho zootécnico foi influenciado diretamente pelos métodos de controle, em que os frangos alojados sobre a cama fermentada, associada ou não à desinfecção por amônia (G4 e G2, respectivamente), tiveram conversão alimentar menor (Tabela 1) e ganho de peso maior (Tabela 2), sendo estes os grupos com melhor desempenho zootécnico.

Diarreia e redução do ganho de peso foram observadas em todos os grupos testados.

O aparecimento de sinais clínicos e lesões macroscópicas no intestino de uma ave infectada por Eimeria spp. depende da quantidade de oocistos esporulados ingeridos, localização do parasito nas vilosidades e da resposta imune do hospedeiro (GUZMAN et al., 2003). Observou-se que o grupo controle (G1) apresentou escore de lesões significativamente maior que os dos demais grupos $(\mathrm{P}<0,05)$, com um grau médio de $3,1 \pm 0,57$, sendo este indicativo de maior severidade das lesões intestinais. Nesse grupo, as lesões macroscópicas variaram do grau 2 (uma ave) até o grau 4 (duas aves). No Grupo 2, a maioria das aves apresentou lesões que variaram de grau 1 (7 aves) até o grau 2 (3 aves), com uma média de $1,3 \pm 0,48$. No Grupo 3 , a média das lesões foi de 2,3 \pm 0.95 , com seis aves apresentando lesões do grau 3. No Grupo 4, apenas uma ave apresentou lesões intestinais de grau 2, sendo que as nove restantes tiveram lesões de grau 1 , com uma média de $1,1 \pm 0,32$ graus de lesões.

De acordo com GUZMAN et al. (2003), a redução da carga de oocistos diminui a severidade das lesões intestinais e, consequentemente, os sinais clínicos. Como houve redução do número de oocistos nos grupos de cama fermentada, isso pode explicar a redução da severidade das lesões intestinais desses frangos. Observou-se que, como a desinfecção não reduziu a carga de oocistos na cama, consequentemente, não ocorreu redução de severidade de lesões intestinais nesses frangos.

\section{CONCLUSÃO}

A associação da desinfecção com amônia quaternária à fermentação da cama de frango não

Tabela 2 - Valores médios dos pesos semanais (7, 14, 21, 28 e 35 dias) em frangos de corte infectados com Eimeria acervulina, por oocistos na cama reutilizada, após tratamentos de controle da coccidiose.

\begin{tabular}{|c|c|c|c|c|c|}
\hline \multirow[t]{2}{*}{ Grupos } & \multicolumn{5}{|c|}{-Datas das pesagens (dias)-- } \\
\hline & 7 & 14 & 21 & 28 & 35 \\
\hline G1 (Controle) & $153 \pm 6,5 b$ & $387 \pm 15,7 \mathrm{a}$ & $673 \pm 24,3 b$ & $1.180 \pm 44,9 \mathrm{~b}$ & $1.450 \pm 47,3 \mathrm{~b}$ \\
\hline G2 (Fermentação) & $176 \pm 3,9 \mathrm{c}$ & $445 \pm 10,4 \mathrm{~b}$ & $725 \pm 18,7 \mathrm{c}$ & $1.274 \pm 43,7 \mathrm{c}$ & $1.587 \pm 63,4 \mathrm{~d}$ \\
\hline G3 (Amônia quaternária) & $165 \pm 9,6 \mathrm{~b}$ & $393 \pm 8,21 \mathrm{a}$ & $670 \pm 29,1 \mathrm{~b}$ & $1.163 \pm 49,7 \mathrm{~b}$ & $1.535 \pm 57,8 \mathrm{c}$ \\
\hline G4 (Ferm. + Amônia) & $182 \pm 7,6 \mathrm{c}$ & $452 \pm 14,3 \mathrm{~b}$ & $710 \pm 22,8 \mathrm{c}$ & $1.250 \pm 41,3 \mathrm{c}$ & $1.599 \pm 51,0 \mathrm{~d}$ \\
\hline
\end{tabular}

(abcd) Valores do mesmo parâmetro seguidos de letras minúsculas diferentes na mesma coluna indicam valores estatisticamente diferentes pelo Teste Tukey $(\mathrm{P}<0,05)$. Unidade de medida: gramas $(\mathrm{g})$. 
potencializou o controle da coccidiose e a realização da desinfecção da cama sem associação à fermentação não apresentou nenhuma efetividade na redução de oocistos de E. acervulina.

\section{AGRADECIMENTOS}

À Empresa Brasileira de Pesquisa Agropecuária (EMBRAPA) e Laboratório BIOVET, Brasil.

\section{COMITÊ DE ÉTICA E BIOSSEGURANÇA}

Sob protocolo nำ 050/2008.

\section{REFERÊNCIAS}

CHAPMAN, H.D. et al. Guidelines for evaluating the efficacy and safety of live anticoccidial vaccines and obtaining approval for their use in chickens and turkeys. Avian Pathol, v.34, p.279290, 2005. Disponível em: <http://www.tandfonline.com/doi/abs /10.1080/03079450500178378>. Acesso em: 04 jan. 2012. doi : $10.1080 / 03079450500178378$

COSTA, C.A.F.; ÁVILA, V.S. Efeito da idade das aves e da reutilização e manejo da cama de aviário sobre a coccidiose em frangos de corte. Concórdia: Embrapa Suínos e Aves, 2003. 5p. (Embrapa Suínos e Aves. Comunicado Técnico, 327). Disponível em: 〈www.cnpsa.embrapa.br〉. Acesso em: 22 dez. 2011.

DAUGSCHIES, A. et al. Development and application of a standardized assay for chemical disinfection of coccidian oocysts. Vet Parasitol, v.103, p.299-308, 2002. Disponível em: <http:// www.sciencedirect.com/scien ce/article/pii/S0304401701005817>. Acesso em: 04 jan. 2012. doi: 10.1016/S0304-4017(01)00581-7.

GABRIEL, L. et al. Effects of whole wheat feeding on the development of coccidial infection in broiler chickens until marketage. Anim Feed Sci and Technol, v.129, n.3-4, p.279-303, 2006. Disponível em: <http://www.sciencedirect.com/science/article/pii/ S0377840106000149>. Acesso em: 23 dez. 2011. doi:10.1016/j. anifeedsci.2006.01.004.

GUZMAN, V.B. et al. A comparison between IgG antibodies against Eimeria acervulina, E. maxima and E. tenella oocyst shedding in broiler-breeders vaccinated with live anticoccidial vacines. Vaccine, v.21, p.4225-4233, 2003. Disponível em: <http://www. sciencedirect.com/science/article/pii/S0264410X03004626>. Acesso em: 04 jan. 2012. doi:10.1016/S0264-410X(03)00462-6.

JOHNSON, J.; REID, W.M. Anticcocidial drugs: lesion scoring techniques in battery and floor-pen experiments with chickens.
Exp Parasitol, v.28, p.30-36, 1970. Disponível em: <http:// www.sciencedirect.com/science/article/pii/0014489470900639>. Acesso em: 03 jan. 2012. doi:10.1016/0014-4894(70)90063-9.

GUIMARÃES, J.S.J. et al. In vitro evaluation of the disinfection efficacy on Eimeria tenella unsporulated oocysts isolated from broilers. Rev Bras Parasitol Vet, v.16, n.2, p.6771, 2007. Disponível em: <http://www.cbpv.com.br/rbpv/ documentos/1622007/c16267_71.pdf>. Acesso em: 03 jan. 2012.

KAWAZOE U. et al. Characterization and histopathological observations of a selected Brazilian precocious line of Eimeria acervulina. Vet Parasitol, v.131,p.5-14,2005. Disponível em: <http:// www.sciencedirect.com/science/article/pii/S0304401705001329>. Acesso em: 04 jan. 2012. doi:10.1016/j.vetpar.2005.03.038.

LILLEHOJ, E.P.; LILLEHOJ, H.S. Avian coccidiosis. A review of acquired intestinal immunity and vaccination strategies. Avian Dis, v.44, p.408-425, 2000. Disponível em: <http://www.jstor.org/ pss/1592556>. Acesso em: 03 jan. 2012.

OVIEDO-RONDÓN, E.O. Tecnologias para mitigar o impacto ambiental da produção de frangos de corte. Rev Brasileira de Zoot, v.37, p.239-252, 2008. Disponível em: <http://dx.doi.org/10.1590/ S1516-35982008001300028>. Acesso em: 04 jan. 2012.

PENG, X. et al. Evaluation of the effect of temperature on the die-off rate for Cryptosporidium parvum oocysts in water, soils, and feces. Appl and Environ Microb, v.74, p.7101-7107, 2008. Disponível em: <http://aem.asm.org/content/74/23/7101.full>. Acesso em: 23 dez. 2011. doi: 10.1128/AEM.01442-08.

SANTOS, T.M.B. et al. Effects of broiler stocking density and poultry litter reuse in broiler performance and poultry litter production. Rev Portuguesa de Ci Vet, v.100, p.4552, 2005. Disponível em: <http://www.fmv.utl.pt/spcv/ edicao/3_2005/100_45_52.htm>. Acesso em: 22 dez. 2011.

SHEATER, A.L. The detection of intestinal protozoa and mange parasites by a flotation technique. J Comp Ther, v.36, p.266-275, 1923.

STROUT, R.G. et al. In vitro cultivation of Eimeria acervulina (Coccidia). Experim Parasitol, v.17, p.241-246, 1965. Disponível em: 〈http://dx.doi.org/10.1016/0014-4894(65)90064-0>. Acesso em: 07 jun. 2012.

WICHUK, K.M.; MCCARTNEY, D. A review of the effectiveness of current time temperature regulations on pathogen inactivation during composting. Journal of Environ Engin and Sci, v.6, p.573-586, 2007. Disponível em: <http://www.nrcresearchpress. com/doi/abs/10.1139/S07-011>. Acesso em: 04 jan. 2012. doi. 10.1139/S07-011. 